\title{
CRYOCONSERVATION DU SPERME DE TRUITE ARC-EN-CIEL (Salmo gairdneri R.)
}

\author{
M. LEGENDRE, R. BILLARD \\ Laboratoire de Physiologie des Poissons, I.N.R.A. \\ 78350 JOUY-EN-JOSAS, France
}

\section{INTRODUCTION}

La production de poissons en pisciculture se développe activement depuis quelques décennies et fait de plus en plus appel aux méthodes d'amélioration empruntées à la zootechnie.

Les problèmes que rencontre le pisciculteur (essentiellement Salmoniculture en France) sont nombreux et classiques de tous les types d'élevages et portent sur la pathologie. l'alimentation et la reproduction. L'un des problèmes les plus spécifiques est le caractère très saisonnier de la reproduction qui rend difficile un approvisionnement régulier du marché. Il est donc fort utile de maitriser l'époque de reproduction et il existe differentes approches pour étaler la production de juvéniles au cours de l'année. On peut déplacer l'époque de la fraie (manipulation photopériodique ou traitement hormonal), ou conserver les gamètes ou les embryons.

Article available at http://www.kmae-journal.org or http://dx.doi.org/10.1051/kmae:1980006 
Le présent travail porte sur la cryoconservation du sperme, qui présente d'autre part des applications plus ponctuelles; elle facilite les opérations d'insémination artificielle et autorise des croisements ou hybridations d'animaux. géographiquement éloignés ou dont l'époque de reproduction est différente.

Les informations bibliographiques portant sur la congelation du sperme de poisson sont relativement limitees et concernent surtout les Saimonidés, le Brochet, la Carpe et quelques especces de poissons marins

Pour les Salmonidés, malgré de nombreux travaux, la littérature dépeint une situation qui reste confuse. HOYLE et IDLER (1968), puis TRUSCOTr et IDLER (1909) obtiennent un succès très partiel après congèlation du sperme de Saumon atlantique, respectivement 12 et $19 \%$ de fécondation; GRAYBILL et HORTON (19ô) obtiennent également un succès limité chez la Truite arc-en-ciel (18\%). OTT et ORTON (1971 a, b) rapportent de bons résultats chez le Saumon chinook, le Saumon coho et la Truite arc-en-ciel (59\%); néanmoins, la quantité de sperme utilisée lors de l'insémination reste élevée, et. pour la Truite, leur méthode de congélation reprise dans de nombreux laboratoires ne s'est pas révélée très performante (BILLARD, non publié).

Plus récemment, STEIN et al. (1978) congèlent avec succès le sperme de Truite arc-en-ciel $(80 \%)$ et fario $(70 \%$ ) alors que STOSS et al. (1978) obtiennent des résultats très variables selon les mâles $(2$ à $80 \%$ ) et seulement $31 \%$ de fécondation avec la tech nique de STEIN. Enfin, MOUNIB (1978) annonce $80 \%$ de fécondation après congélation du sperme de Saumon et ERDAHL et GRAHAM (1978) proclament avoir obtenu $90 \%$ de fécondation chez la Truite arc-en-ciel (il est cependant regrettable que la nature du dilueur de congélation employé n'ait pas été mentionnée dans la publication).

Pour le Brochet, seules deux ètudes ont été réalisées : STEIN (1978) obtient $25 \%$ de fécondation et DE MONTALEMBERT et al. (1977), en utilisant le même dilueur de congélation, obtiennent de bons résultats avec un mélange de sperme (50\%) mais des résultats variables avec des échantillons individuels ( 0 à $68 \%$ ).

Pour la Carpe, le seul véritable succès est rapporté par MOCZARSKI (1977) qui obtient $50 \%$ de fécondation. STEIN (1978), malgrè une importante motilité du sperme au dégel, ne peut obtenir de fécondations. De son côté BILLARD (non publié) n'obtient pas plus de $20 \%$ de fécondation après décongélation.

D'une manière générale, la non reproductibilité des résultats obtenus pour différents individus d'une même espèce, les succès souvent partiels et l'imprécision des conditions experimentales de certains comptes rendus (quantité de sperme utilisée lors de l'insémination, nature des dilueurs de congélation et de décongélation) ne permettent pas de conclure à l'existence d'une technique de congélation du sperme satisfaisante pour ces espèces d'eau douce.

L'objectif du présent travail réalisé chez la truite arc-en-ciel a été de définir une technique de congélation simple et fiable, applicable sur le terrain. L'expérimentation a porté sur le complexe dilueur + cryoprotecteur et les vitesses de congélation et de décongélation. La variabilité inter-mâles dans l'aptitude du sperme à la congélation a été prise en consideration. Les critères d'appréciation de la qualité du sperme après dégel ont èté la motilité, le pouvoir fécondant, ainsi que la survie durant le développement em. bryonnaire et la résorption vitelline. Une partie de ce travail a déjà fait l'objet d'une présentation (LEGENDRE et BILLARD, 1980).

\section{MATERIEL ET METHODES}

\section{1) Matériel animal et prélèvement des gamètes}

L'expérimentation a eu lieu en décembre 1978, janvier et février 1979. Les géniteurs âgés de 2 à 3 ans, fournis par des piscicultures privées, ont été stockés au laboratoire à une température variant entre 6 et $12^{\circ} \mathrm{C}$. 
Les mâles, entrés en pleine spermiation au début de décembre, sont prélevés au hasard dans un lot d'une trentaine d'individus, ceux-ci, à jeun depuis au moins $48 \mathrm{~h}$ sont anesthésiés au phénoxyéthanol (MERK) $(0.3 \mathrm{ml} / 1)$ La papille génitale est séchée et le sperme émis par pression abdominale est recueilli dans des tubes à hémolyse placés dans la glace fondante puis stockés sur une paillasse réfrigérée $\left(4^{\circ} \mathrm{C}\right)$

Les échantillons contaminés par de l'urine ou des fécès sont éliminés, et seuls sont définitivement gardés pour des essais de congélation ceux présentant une forte motilité (4: cf tableau 4). Selon les cas, un pool est constitué par mélange du sperme de plusieurs mâles ( 3 à 4 ) de façon à limiter l'influence d'un mauvais sperme et pour disposer d'une quantité de matériel plus importante.

La concentration en spermatozoides des différents spermes utilisés, est déterminée a posteriori par comptage sur hématimètre après dilution au $1 / 2000^{m o}$ dans une solution saline à $8 \%$.

Les ovules sont prélevés par massage abjominal sur des $f \in$ melles ayant ovulé récemment (moins de 8 jours) et les pontes présentant des signes de vieillissement (ovules à vitellus hétérogène ou polarisé) sont rejetées (lors d'une insémination réalisée en août, de tels ovules, seuls disponibles, ont cependant été utilisés). Un pool d'ovules provenant d'au minimum 4 femelles est toujours constitué pour les tests de fécondation, de façon à uniformiser l'effet femelle.

\section{2) Congélation}

\section{DILUEURS DE CONGELATION}

Deux milieux seuls ou en association ont servi de base à la recherche d'un dilueur te congélation.

\section{- Milieu de MOUNIB :}

Ce milieu est dérivé d'un dilueur expérimenté pour la congélation des enzymes do métabolisation du $\mathrm{Co}_{2}$ des spermatozoides (MOUNIB et al., 1968; MOUNIB, 1974). II a permis de congeler avec succès le sperme de Saumon ( $80 \%$ de fécondation) et de Morue $(59,4 \%$ ) (MOUNIB, 1978). Sa composition est donnée dans le tableau 1

\section{Tableau 1 : Composition du dilueur de MOUNIB (mM/1).}

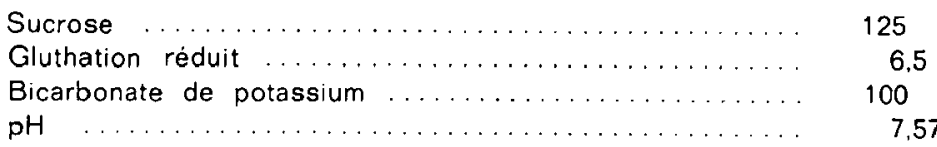

\section{- Milieu MENEZO INRA B.}

Ce milieu, initialement conçu paur des cultures cellulaires (MENEZO, 1976), s'est éga'ement avéré un dilueur efficace lors de la congélation du sperme de poissons marins (MAUVIOT et BILLARD. non publié), mais a donné des résultats héterogènes dans un début d'expérimentation chez la Truite (BILLARD, 1979).

Une caractéristique du dilueur de congèlation est de maintenir les spermatozoides imnobiles. En effot. la durée de motilite des spermatozoides de Salmonidés qui intervient a)rès ajdition d'eau ou de dilueur d'insémination (DIA 532) est brèvs, entre 30 et 60 s-condes, après quoi le pouvoir fécondant est irréversiblement perdu. "l est donc impératif do maintonir l'état immobile qui caracterise le sperme pur, jussu'à la c'écongélation et 
l'insémination. L'immobilité est assurée par le $\mathrm{K}_{2} \mathrm{CO}_{3}$ et le sucrose dans le dilueur MOUNIB et particulièrement par le $\mathrm{KCl}$ dans le milieu MENEZO.

Dans un souci d'amélioration, des composés organiques ont été additionnés au dilueur essentiellement minéral de MOUNIB :

- La * Bovine Serum albumine. (BSA) (SIGMA - grade V) dont l'action favorable a déjà été reconnue lors de la congélation du sperme de Bar (MAUVIOT et BILLARD, non publié) et de certains Mammifères dont le Vérat (PAQUIGNON, communication personnelle).

- Le jaune d'couf qui a été couramment utilisé pour la congélation du sperme de Mammifères et a également permis de bons résultats chez les Poissons (OTT et HORTON. 1971 b. STEIN, 1978).

Au total, 7 combinaisons ont été utilisées (tableau 2).

Tableau 2 : Dilueurs testés ot abréviations.

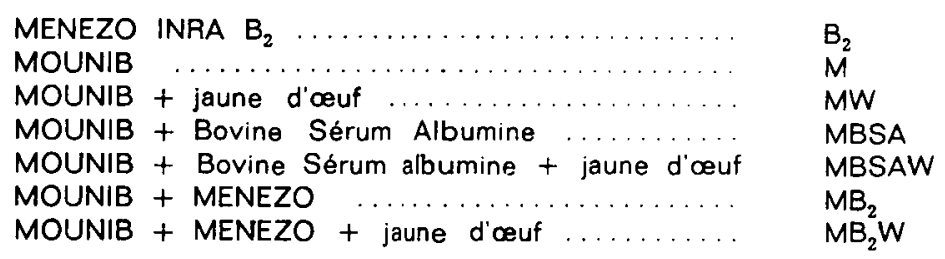

La BSA (Sigma fraction $V$ ) est ajoutée aux dilueurs à raison de $10 \mathrm{mg} / \mathrm{ml}$.

Le jaune d'œuf (jaune d'œuf au téllurite de potassium : Institut Pasteur) est ajoutè à une concentration de $10 \% \mathrm{Vol} / \mathrm{Vol}$ total (avec cryoprotecteur).

Le mélange $\mathrm{MB}_{2}$ est effectué dans la proportion de 1 (vol/vol).

\section{LE CRYOPROTECTEUR}

Le Diméthylsufoxide (DMSO) utilisé invariablement à la concentration de $10 \%$ (vol./vol. total) a été choisi pour deux raisons essentielles :

- au cours de tests comparatifs chez le Saumon et la Truite, il s'est révélé plus efficace que le glycérol, l'éthylène glycol ou le polyvinyl pyrolidone (TRUSCOT et al.. 1968 ; OTT et HORTON, 1971 b) ou équivalent à l'éthylène glycol (ERDAHL et GRAHAM, 1978).

Sa pénétration rapide dans les cellules (MERYMAN. 1971) permet de limiter la durée d'équilibration, rapidement néfaste dans le cas du sperme de Bar (BILLARD et DUPONT, 1975), et de procéder avec succès à la congélation sans équilibration, immédiatement apres dilution du sperme (STOSS, 1978 ; MOUNIB, 1978).

\section{DILUTION DU SPERME AVANT CONGELATION}

Le dilueur de MOUNIB, peu stable, est préparé avant chaque essai. Le DMSO et le jaune d'œuf sont ajoutés au dilueur de congélation, immédiatement avant mélange sperme-dilueur, réalisé lorsque leur température respective est équilibrée à $4^{\circ} \mathrm{C}$.

Pour chaque dilueur, trois taux de dilution du sperme sont testés :

$1 / 1,1 / 3,1 / 9:$ volume de sperme

volume de dilueur (avec DMSO)

DMSO, BSA et jaune d'œuf après dilution du sperme, sont exprimées dans le tableau 3 pour chaque dilueur et dilution 


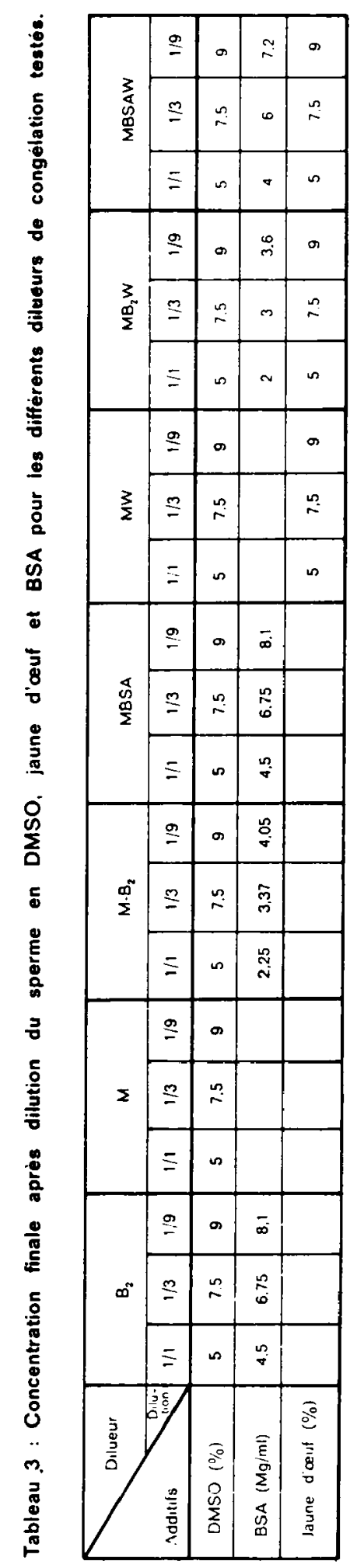




\section{PROCEDURE DE CONGELATION}

Deux procédures de congélation ont èté employées (fig. 1) en mettant en œuvre deux sources de froid : la a carboglace - et l'azote liquide.

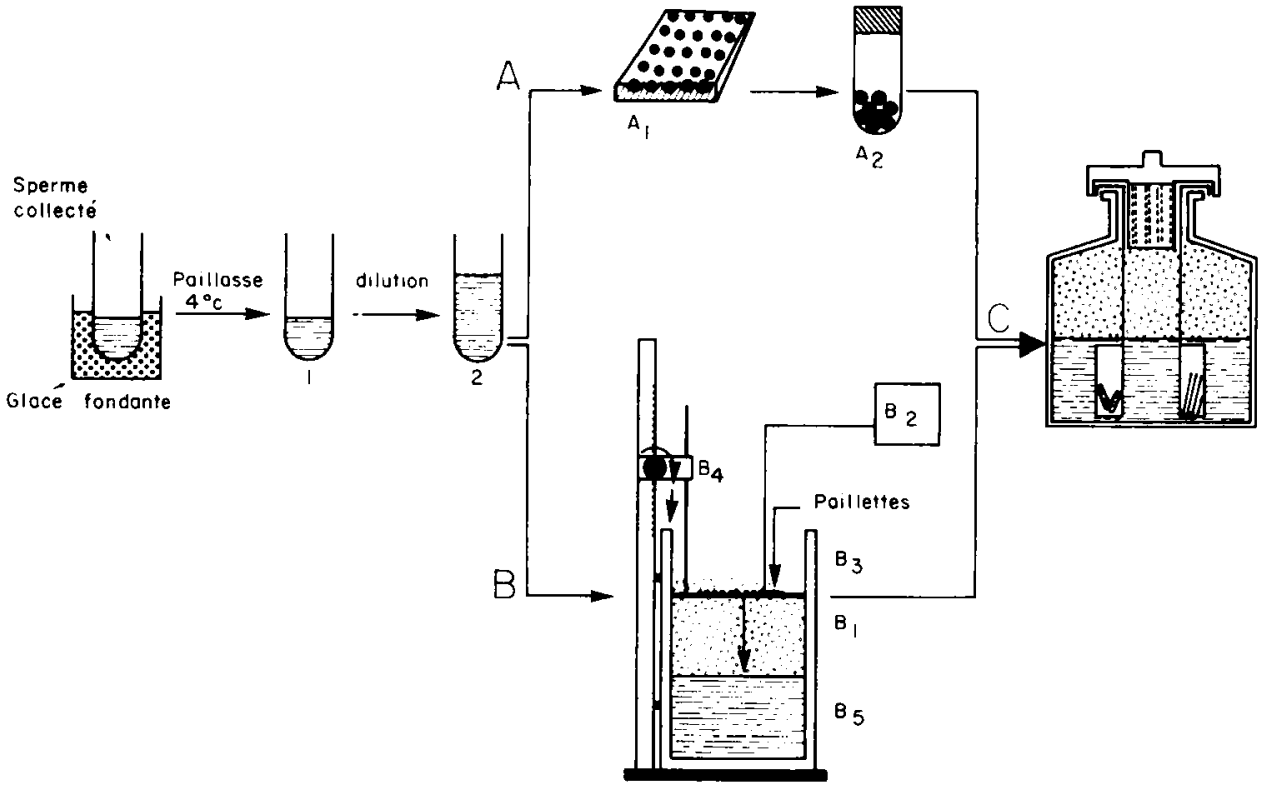

Figure 1 : Schéma récapitulatif des opérations pour la congelation du sperme chez la truite Arc-en-ciel.

La procédure de congélation débute immédiatement après l'addition au sperme pur (1) du dilueur + cryoprotecteur (2).

Deux méthodes sont utilisées :

A) Congélation en pellets de $100, \ldots l$ sur des plaquettes de carboglace $\left(A_{1}\right)$; groupés par lots expérimentaux dans des tubes à hémolyse $\left(A_{2}\right)$ les pellets sont stockés grâce à un canister immergé dans l'azote liquide (C).

B) Congélation dans des vapeurs d'azote liquide $\left(B_{1}\right)$ après une rapide répartition du sperme dilué en paillettes de $250 \mu \mathrm{l}$. La vitesse de congélation, contrôlée par un enregistreur de température $\left(B_{2}\right)$ est maintenue constante par abaissement progressif (à l'aide d'une crémaillère $\left(B_{4}\right)$ du plateau $\left(B_{3}\right)$ supportant les paillettes; à $-30^{\circ} \mathrm{C}$ celui-ci est immergé dans l'azote $\left(B_{5}\right)$. Le stockage est identique à celui des pellets (C).

- Congélation en pellets (carboglace)

La congélation du sperme en pellets est réalisèe selon la technique de NAGASE (1904) : à l'aide d'une micropipette (Gilson P 200) des gouttes de $100 \mu$ de sperme dilué sont simplement déposées dans de petites dépressions pratiquées à la surface d'une plaquette de carboglace $\left(-79^{\circ} \mathrm{C}\right)$. La vitesse de congélation n'a pas été mesurée, mais on sait as'elle n'est pas uniforme en tous points du pellet (LIGHTFOOT et al., 19:9).

- Congélation en paillettes (azote liquide)

Le sperme dilué est rapidement réparti en paillettes de $250 \mu \mathrm{l}$, celles-ci sont disfosées horizontalement sur un plateau parallèle à la surface de l'azote liquide, selon la technique proposée par DUPONT (1976). L'abaissement progressif du plateau permet do maintenir constante la vitesse de congélation choisie; celle-ci est contrôlée grâce à une 
thermosonde glisseje dans l'une des paillettes (contenant le dilueur + le cryoprotecteur) et reliée à un enregistreur de température. Lorsque la température, qui ainsi mesurée reste proche de celle du sperme, atteint $-30^{\circ} \mathrm{C}$. le plateau supportant les paillettes est immergé dans l'azote liquide $\left(-196^{\circ} \mathrm{C}\right)$.

\section{STOCKAGE DU SPERME CONGELE}

Une fois congelé, les pellets sont rapidement groupés par lots expérimentaux dans des tubes à hèmolyse préalablement refroidis par contact avec la carboglace, placés en canister puis immédiatement immergés dans l'azote liquide. Les paillettes sont également placées en canister et transférées dans une bonbonne de stockage (fig. 1). Le niveau d'azote liquide dans la bonbonne est régulièrement complété (tous les 15 jours)

\section{3) Décongélation}

Les pellets sont fondus en une dizaine de secondes, directement en présence des ovules, par agitation dans le dilueur d'insémination artificielle (DIA 532) généralement utilisé à température ambiante $\left(10^{\circ} \mathrm{C}\right)$. L'influence de vitesses supérieures de décongélation a été testée en utilisant le DIA 532 à des températures plus élevées $\left(15,20,25^{\circ} \mathrm{C}\right)$. Le sperme contenu dans les paillettes est amené à l'état liquide après un passage de 15 secondes dans un bain-marie à $25^{\circ} \mathrm{C}$.

\section{4) Critères de survie des spermatozoìdes après congélation}

\section{la mOTILITE}

L'intensité et la durée de motilité sont appréciées.

Tableau 4 : Echelle arbitraire pour exprimer la motilité des spermatozoides (d'après SAN. CHEZ-RODRIGUEZ, 1975).

\begin{tabular}{|c|c|}
\hline Valeur & Observations \\
\hline 5 & $\begin{array}{l}\text { Tous les spermatozoijes se deplacent vigoureusement; impossible de } \\
\text { fixer la vue sur aucun d'entre eux. }\end{array}$ \\
\hline 4 & $\begin{array}{l}\text { La majorité des spermatozoides se déplace encore rapidement : seuls } \\
\text { quelques-uns sont visibles du fait de leur déplacement plus lent. }\end{array}$ \\
\hline 3 & $\begin{array}{l}\text { Les spermatozoides présentent trois comportements (en nombre égal) : } \\
\text { - soit ils se déplacent vigoureusement, } \\
\text { - soit ils se déplacent lentement, } \\
\text { - soit ils sont immobiles. }\end{array}$ \\
\hline 2 & $\begin{array}{l}\text { Peu de spermatozoìdes se déplacent rapidement; quelques-uns se dé- } \\
\text { placent lentement. La majorité des spermatozoides est immobile. }\end{array}$ \\
\hline 1 & Seuls quelques spermatozoides ont une légère agitation. \\
\hline 0 & Tous les spermatozoides sont immobiles. \\
\hline
\end{tabular}


La mesure de l'intensité de motilite est systematiquement effectuée et après observation des spermatozoïdes au microscope à contraste de phase (X 100), une note arbitraire de 0 à 5 est donnée selon l'èchelle présentèe dans le tableau 4 . Après décongélation, du fait des faibles intensités observées, des degrés intermédiaires sont employés; ces degrés correspondent aux notes de l'échelle précédente affectées d'un coefficient - ou + . Par exemple, l'échelon $0+$ est utilisé lorsque 0 à 2 spermatozoides en mouvement sont visibles par champs.

La durée de motilité initiale a également èté mesurée. Elle se définit par le temps écoulé entre l'addition du DIA 532 au sperme et le moment ou l'intensité de mouvement chute brutalement (CARPENTIER, 1977).

\section{- le pouvoir fecondant}

Pour chaque lot expérimental, environ 200 ovules placés dans une boite sèche sont mis en présence de $10 \mathrm{ml}$ de DIA 532 (solution saline tamponnée à pH 9, BILLARD, 1977), et d'un volume de 10 ou $100 \mu$ de sperme à tester (dilution respective de $10^{-3}, 10^{-2}$ ). Le cas échéant, le volume de sperme à l'insémination est corrigè pour tenir compte de la dilution de congélation (technique de double dilution, BILLARD et al., 1974). Après une agitation rapide, les ovules sont laissés au repos 15 minutes, puis sont transférés dans des incubateurs placés en eau recyclèe, épurée, saturée en oxygène et thermorégulèe à $10^{\circ} \mathrm{C}$ (PETIT, 1973).

Les œufs sont triés et dénombrès après une duree d'incubation de 10 ou 30 jours (100 ou 300 degrès-jours) : - à 100 degrés-jours, les embryons sont visibles après éclaircissement dans une solution de Stockard (5 vol. de formol, 6 vol. de glycérol, 4 vol. d'acide acétique pour 85 vol. d'eau); - à 300 degrés-jours, peu avant l'éclosion (320 à 350 degrés-jours), aucun éclaircissement n'est nécessaire, les œufs embryonnés, alors au stade œillè, sont aisément identifiables.

\section{L'ASPECT NORMAL DU DEVELOPPEMENT EMBRYONNAIRE ET LARVAIRE}

L'aspect normal des populations obtenues à partir de sperme congelé est évalué par leur taux de mortalité et l'observation d'éventuelles anomalies de développement. La mortalité des embryons en fin de développement embryonnaire et à l'éclosion est définie $\mathrm{Nb}$. d'œufs œillés

par le pourcentage d'éclosion : $\frac{\text { Nb. d'éclos }}{} \times 100$. Le comptage des œufs œillés est pratiqué à 300 degrés-jours, dans une coupelle reposant sur de la glace fondante ; ceux$\mathrm{ci}$, séparés des ovules non fécondés, sont ensuite réincubés. Un nouveau comptage est effectué après éclosion et les alevins sont alors placés dans des bacs spacieux en eau recyclée à $10-12^{\circ} \mathrm{C}$.

Durant la période de résorbtion vitelline, les morts sont dénombrés régulièrement et $\mathrm{Nb}$. de morts

enlevés des bacs. Le pourcentage de mortalité s'exprime par : $\frac{\mathrm{Nb} \text {. d'alevins initial }}{\mathrm{Nb}} \times 100$

\section{5) Méthodes statistiques}

Les durées de motilité sont comparees par la méthode des couples ( $T$ ' Student). La comparaison des pourcentages de fécondation est réalisée grâce à différents tests statistiques adaptés à chaque situation expérimentale : test $X^{2}$, test $t$, analyse de variance à deux facteurs. Pour l'analyse de variance, une transformation des données en arc sinus était effectuée lorsqu'elle était jugée nécessaire pour stabiliser la variance résiduelle, et lorsqu'elle concluait à une différence significative, on recherchait les lots expérimentaux homogènes par le test de Duncan. Dans certains cas, pour tester la signification des tendances observées, le test non paramétrique des signes est employé. 


\section{RESULTATS}

1) Influence de la nature du dilueur de congélation sur la motilité des spermatozoides

On constate (tableau 5) que avant congélation et sans DIA, seul le dilueur $B_{2}$

Tableau 5 : Influence de la nature du dilueur de congélation sur la motilité des spermatozoides. Le sperme pur + DIA présente toujours une motilité de 4.

\begin{tabular}{|c|c|c|c|c|c|}
\hline \multirow[b]{2}{*}{ Dilueur } & \multirow[b]{2}{*}{ Dilution } & \multicolumn{2}{|c|}{ Avant congélation } & \multicolumn{2}{|c|}{ Après congélation } \\
\hline & & $\begin{array}{l}\text { Sperme + } \\
\text { dilueur }\end{array}$ & $\begin{array}{c}\text { Sperme + } \\
\text { dilueur + DIA }\end{array}$ & $\begin{array}{l}\text { Spontanée } \\
\text { ds dilueur }\end{array}$ & Avec DIA \\
\hline$M$ & $\begin{array}{l}1 / 1 \\
1 / 3 \\
1 / 9\end{array}$ & $\begin{array}{l}0+ \\
0+ \\
0+\end{array}$ & $\begin{array}{l}4 \\
4 \\
3\end{array}$ & $\begin{array}{l}0+ \\
0+ \\
0+\end{array}$ & $\begin{array}{l}1- \\
1+ \\
2-\end{array}$ \\
\hline MW & $\begin{array}{l}1 / 1 \\
1 / 3 \\
1 / 9\end{array}$ & $\begin{array}{l}0+ \\
0+ \\
0+\end{array}$ & $\begin{array}{l}4 \\
4 \\
4\end{array}$ & $\begin{array}{l}0+ \\
0+ \\
0+\end{array}$ & $\begin{array}{l}1+ \\
2 \\
2-\end{array}$ \\
\hline MBSA & $\begin{array}{l}1 / 1 \\
1 / 3 \\
1 / 9\end{array}$ & $\begin{array}{l}0+ \\
0+ \\
0+\end{array}$ & $\begin{array}{l}4 \\
4 \\
4\end{array}$ & $\begin{array}{l}0+ \\
0+ \\
0+\end{array}$ & $\begin{array}{l}1+ \\
2- \\
2-\end{array}$ \\
\hline MBSAW & $\begin{array}{l}1 / 1 \\
1 / 3 \\
1 / 9\end{array}$ & $\begin{array}{l}0+ \\
0+ \\
0+\end{array}$ & $\begin{array}{l}4 \\
4 \\
4\end{array}$ & $\begin{array}{l}0+ \\
0 \\
0+\end{array}$ & $\begin{array}{l}1+ \\
2 \\
2-\end{array}$ \\
\hline $\mathrm{MB}_{2}$ & $\begin{array}{l}1 / 1 \\
1 / 3 \\
1 / 9\end{array}$ & $\begin{array}{l}0+ \\
0+ \\
0+\end{array}$ & $\begin{array}{l}4 \\
4 \\
4\end{array}$ & $\begin{array}{l}0+ \\
0+ \\
0+\end{array}$ & $\begin{array}{l}1+ \\
2- \\
2-\end{array}$ \\
\hline $\mathrm{MB}_{2} \mathrm{~W}$ & $\begin{array}{l}1 / 1 \\
1 / 3 \\
1 / 9\end{array}$ & $\begin{array}{l}0+ \\
0+ \\
0\end{array}$ & $\begin{array}{l}4 \\
4 \\
4\end{array}$ & $\begin{array}{l}0 \\
0+ \\
0\end{array}+$ & $\begin{array}{l}1+ \\
2- \\
2-\end{array}$ \\
\hline $\mathrm{B}_{2}$ & $\begin{array}{l}1 / 1 \\
1 / 3 \\
1 / 9\end{array}$ & $\begin{array}{l}1- \\
1 \\
2\end{array}$ & $\begin{array}{l}4 \\
4 \\
4-\end{array}$ & $\begin{array}{l}0 \\
0+ \\
0+\end{array}$ & $\begin{array}{l}1- \\
1+ \\
1+\end{array}$ \\
\hline
\end{tabular}

confère aux spermatozoìdes une légère motilité. Avec DIA, la motilité observée est identique à celle du sperme pur. Après congélation (en pellets) et sans DIA, la motilité est pratiquement nulle pour tous les dilueurs; avec dilution par le DIA. la motilite reste faible et voisine pour tous les dilueurs, avec toutefois des résultats légèrement inférieurs pour le $\mathrm{B}_{2}$. Cependant, bien que le nombre de spermatozoides en mouvement soit réduit après congélation, ceux-ci présentent un mouvement rapide et rectiligne. On remarque par ailleurs que des dilutions plus fortes $(1 / 3$ ou $1 / 9)$ sont plus favorables.

La comparaison des durées de motilité initiales n'a pas révélé de différences entre le sperme pur et le sperme dilué, stimulé par le DIA avant congélation. De même, la comparaison des durées de motilité du sperme avant et après congélation n'a pas fait apparaitre de différences, mais ces durées n'ont été mesurées que pour $M 1 / 3$.

2) Influence de la nature du dilueur de congélation sur le pouvoir fécondant des spermatozoides

Tous les résultats présentés ci-dessous correspondent à une dilution d'insémination au $1 / 100$. 
COMPARAISON DES DILUEURS $M$ et $B_{2}$ (tableau 6)

La comparaison des pourcentages de fécondation obtenus montre que le milieu $B_{2}$ donne des résultats très inférieurs à ceux obtenus avec le Mounb $(P<0,001)$. Le milieu $B_{2}$ seul n'a donc pas été retenu comme dilueur de congélation du sperme de truite

Tableau 6 : Comparaison des dilueurs M - B. (en pourcentages de fécondation).

\begin{tabular}{|c|c|c|c|}
\hline DILUEUR & $1 / 1$ & $1 / 3$ & $1 / 9$ \\
\hline$M$ & 2,4 & 71,4 & 31,4 \\
\hline$B_{2}$ & 0 & 31,6 & 12,7 \\
\hline TEMOIN & & 93,7 \\
\hline
\end{tabular}

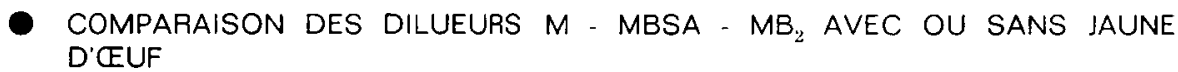

Les résultats sont présentés dans la figure 2

Une comparaison, dilution par dilution, des pourcentages de fécondation moyens obtenus pour chacun des dilueurs montre que les trois dilueurs sans jaune d'œuf ne présentent pas de différences (test $t$ ). La comparaison des trois dilueurs avec jaune d'œuf amène à une conclusion identique.

Par contre le jaune d'œuf permet une amélioration du pouvoir fécondant après congélation, quel que soit le dilueur auquel il est ajouté. Cet effet favorable est très net pour la dilution $1 / 1(P<0,01)$ et persiste pour la dilution $1 / 3(P<0,05)$, excepté pour le dilueur MBSA (à la limite de la signification). Cependant, à la dilution $1 / 9$, le jaune d'œuf n'améliore jamais le pouvoir fécondant. On remarque, d'autre part, que l'augmentation des pourcentages de fécondation s'accompagne d'une importante réduction de la variabilité des résultats, en particulier pour la dilution $1 / 3$, qui donne toujours les meilleurs résultats $(P<0,05)$, à l'exception des dilueurs $M B S A W$ et $M B_{2} W$ pour lesquels à la dilution $1 / 1$ les pourcentages de fécondation sont équivalents

\section{INFLUENCE DU DILUEUR DE CONGELATION AVANT ET APRES CONGELATION}

Dans les résultats précédents, six combinaisons (dilueurs-dilutions) donnent de bons résultats et ne peuvent être différenciées. Chacune de ces combinaisons a été de nouveau testée, après et avant congélation (en observant dans ce dernier cas une durée d'équilibration d'une minute). La différence observée (fig. 3) entre les pourcentages de fécondation avant et après congélation est significative $(P<0,05)$. On constate également (fig. 3) que, avant congélation, quels que soient le dilueur et la dilution, les pourcentages de fécondation ne diffèrent pas de ceux obtenus avec le sperme pur *. Les résultats obtenus,

* Un test équivalent réalisé par ailleurs a montré quaprès $1 \mathrm{mn}$ d'équilibration (délai supérieur à celui qui précède le début de la procédure de congélation), le sperme dilué dans du DMSO seul (à 5 et 10\%) (vol. DMSO/vol. sperme) garde un pouvoir fécondant non différent du sperme pur, méme pour une dilution d'insémination de $10^{-3}$. 

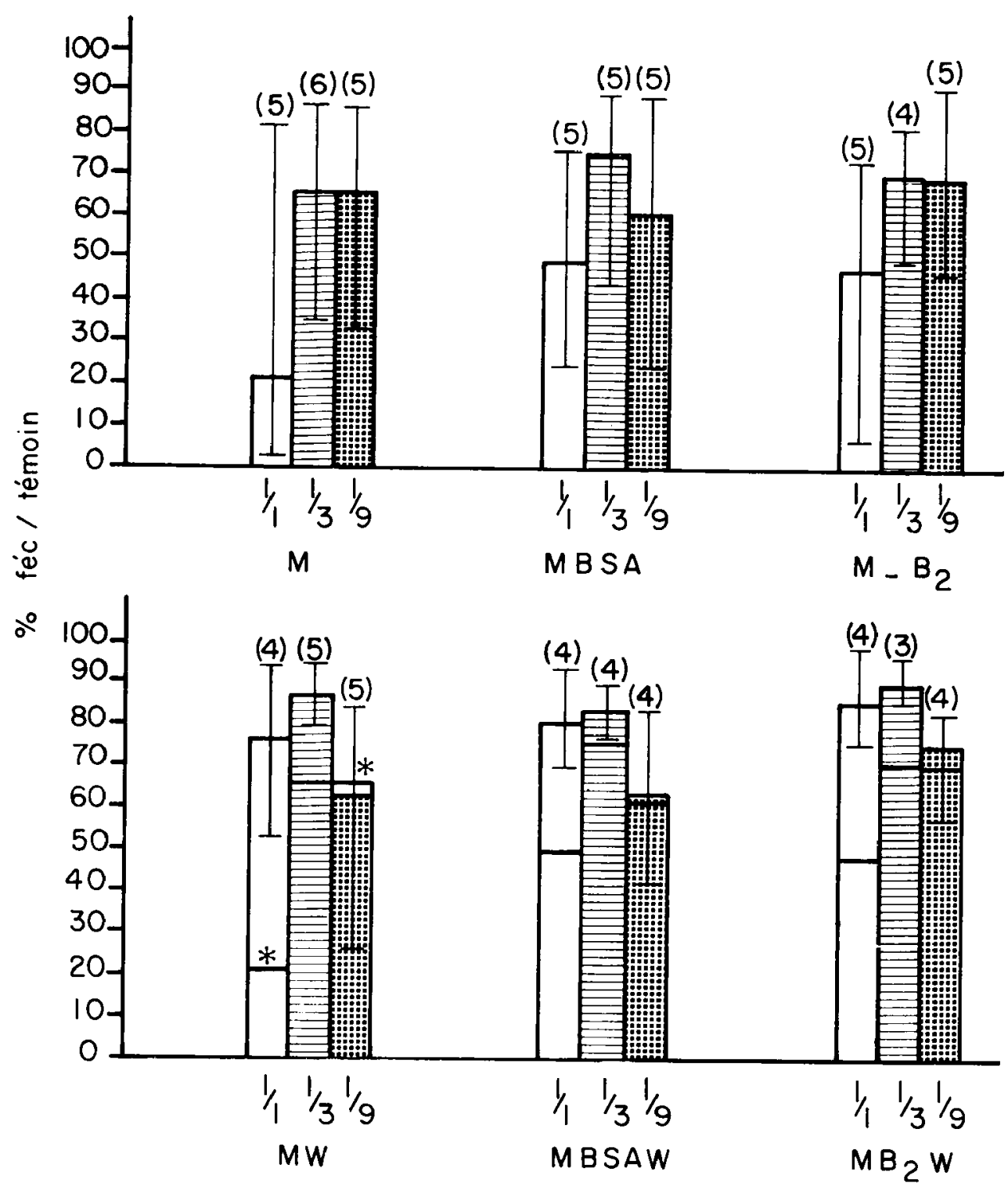

* Dilueurs sans jaune d' ceuf (rappel)

Figure 2 : Comparaison des pourcentages de fécondation obtenus après congélation dans les dilueurs $M, M B S A, M B_{2}$ avec ou sans jaune d'œuf $(W)$ pour 3 taux de dilution du sperme;

Les écarts représentés correspondent aux limites inférieures et aux limites supérieures observées;

Les pourcentages de fécondation obtenus pour les témoins sont tous élevés et conduisent à une référence homogène $(88,8 \%$ en moyenne; $\mathrm{LI}=75 \%$ et LS $=98,4 \%$ ).

() nombre d'observations. 


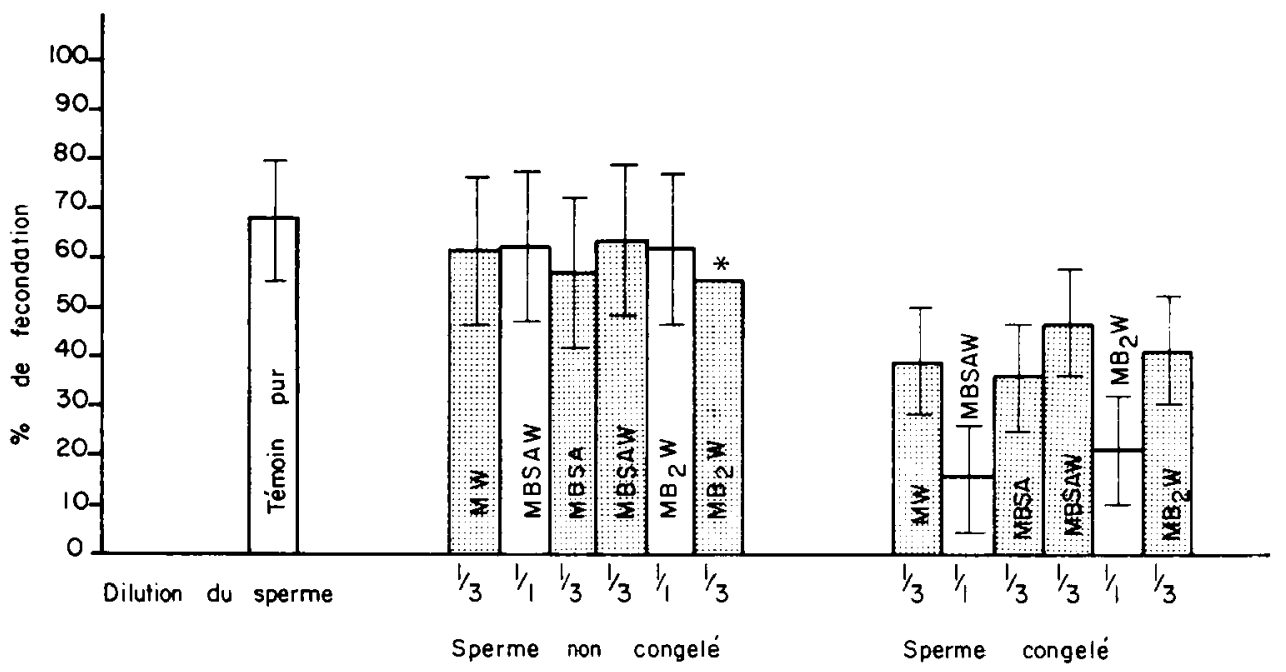

Figure 3 : Influence des dilueurs de congélation et du taux de dilution sur le pouvoir fécondant du sperme avant et après congélation.

Les écarts représentés correspondent à l'intervalle de confiance de la moyenne au risque $5 \%$ pour 4 répétitions (" 2 répétitions seulement).

après congélation confirment que l'addition de BSA ou de $B_{2}$, en plug du jaune d'œuf, au dilueur de Mounib, n'améliore pas le pouvoir fécondant du sperme. L'addition de BSA seule au Mounib semble également avoir un effet favorable sur le pouvoir fécondant, cependant, si l'on tient compte des résultats précédents (fig. 2), cet effet reste moins évident que celui du jaune d'œuf. D'autre part, la dilution $1 / 3$ s'avère, en définitive, plus efficace que la dilution $1 / 1(P<0,001)$.

3) Effet du taux de dilution du sperme lors de l'insemination artificielle

Deux dilutions d'insémination $10^{-3}$ et $10^{-2}$ ont été testées avec du sperme frais et congelé pour trois dilueurs de congélation : $M, M B S A$ et $M W$

Les pourcentages moyens de fécondation obtenus (fig. 4) montrent quavec du sperme congelé dans les trois dilueurs ( $M$, MBSA, MW). l'insémination pour une dilution de $10^{-2}$ (avec le DIA) présente toujours des résultats très supérieurs à ceux obtenus pour une dilution de $10^{-3}(P<0,001)$. Quel que soit le dilueur de congélation utilisé, l'écart entre les pourcentages de fécondation observés pour les deux dilutions d'insémination reste 
sensiblement constant, de l'ordre de $50 \%$, alors que cet écart n'est que de $15 \%$ pour les témoins non congelés. Les résultats obtenus confirment par ailleurs la supérioritè du MW sur les autres dilueurs.

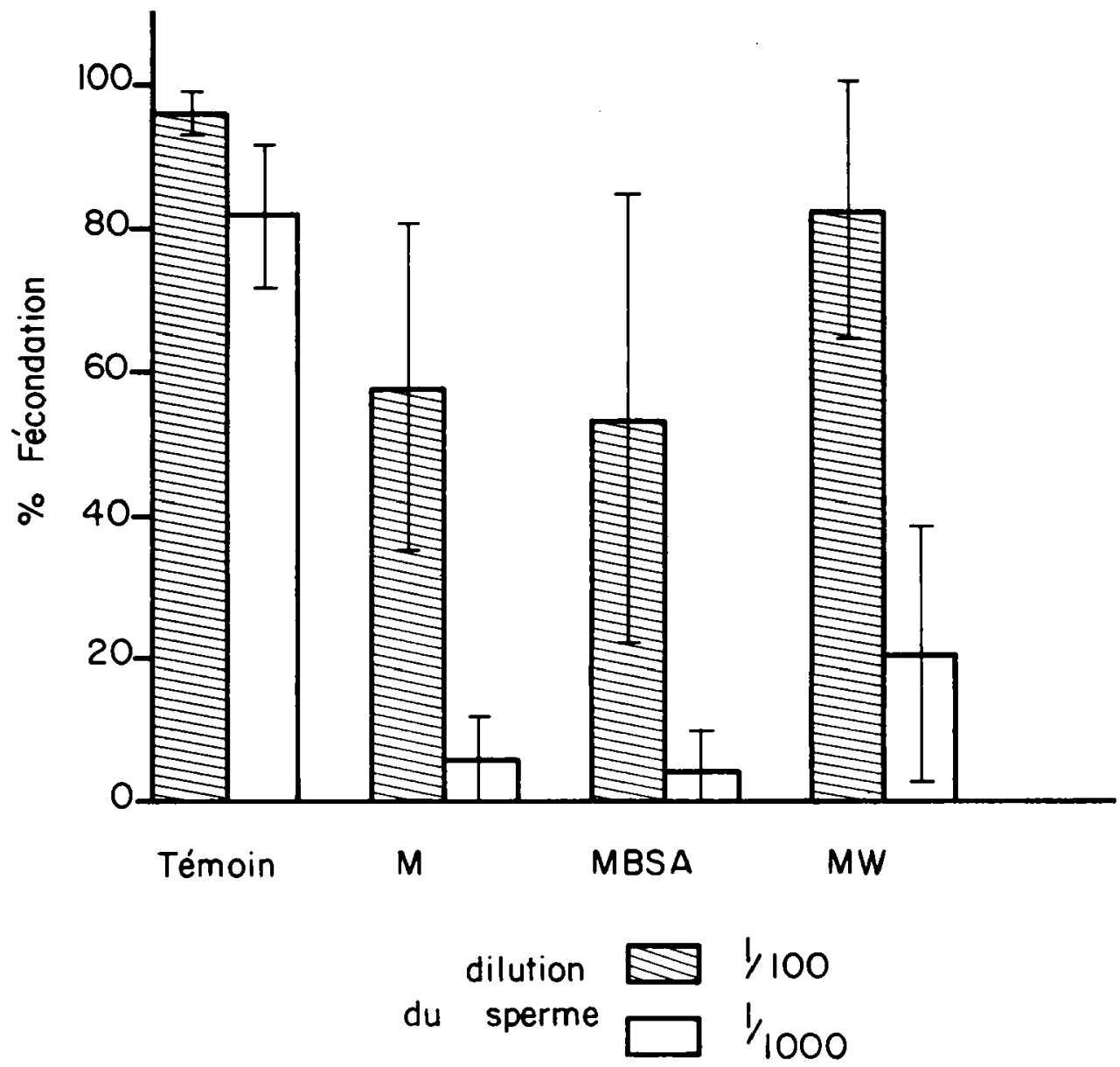

Figure 4 : Influence de la dilution du sperme lors de l'insémination sur le pouvoir fécondant du sperme frais (témoin) et du sperme congelé dans les dilueurs $M$, MBSA, MW.

\section{4) Influence de la vitesse de congélation}

Les pellets de sperme congelè ont èté, soit laissés sur la carboglace, soit immergés après congélation dans l'azote liquide pendant quelques heures. Ils sont laissés à fondre lors de l'insémination dans du DIA 532 utilisé à quatre températures $\left(10,15,20\right.$ et $25^{\circ} \mathrm{C}$ ). Le récipient dans lequel a été réalisée l'insémination, ainsi que les œufs, étant à temáé. rature ambiante $\left(10^{\circ} \mathrm{C}\right)$ la température initiale du DIA $\left(15,20,25^{\circ} \mathrm{C}\right)$ ne se maintient que peu de temps; l'effet propre de la température du DIA sur les gamètes a cependant été testé par un témoin non congelé. Cette expérience a été répétée avec deux dilueurs de congélation : $M$ et $M W$ pour une dilution du sperme de $1 / 3$. 


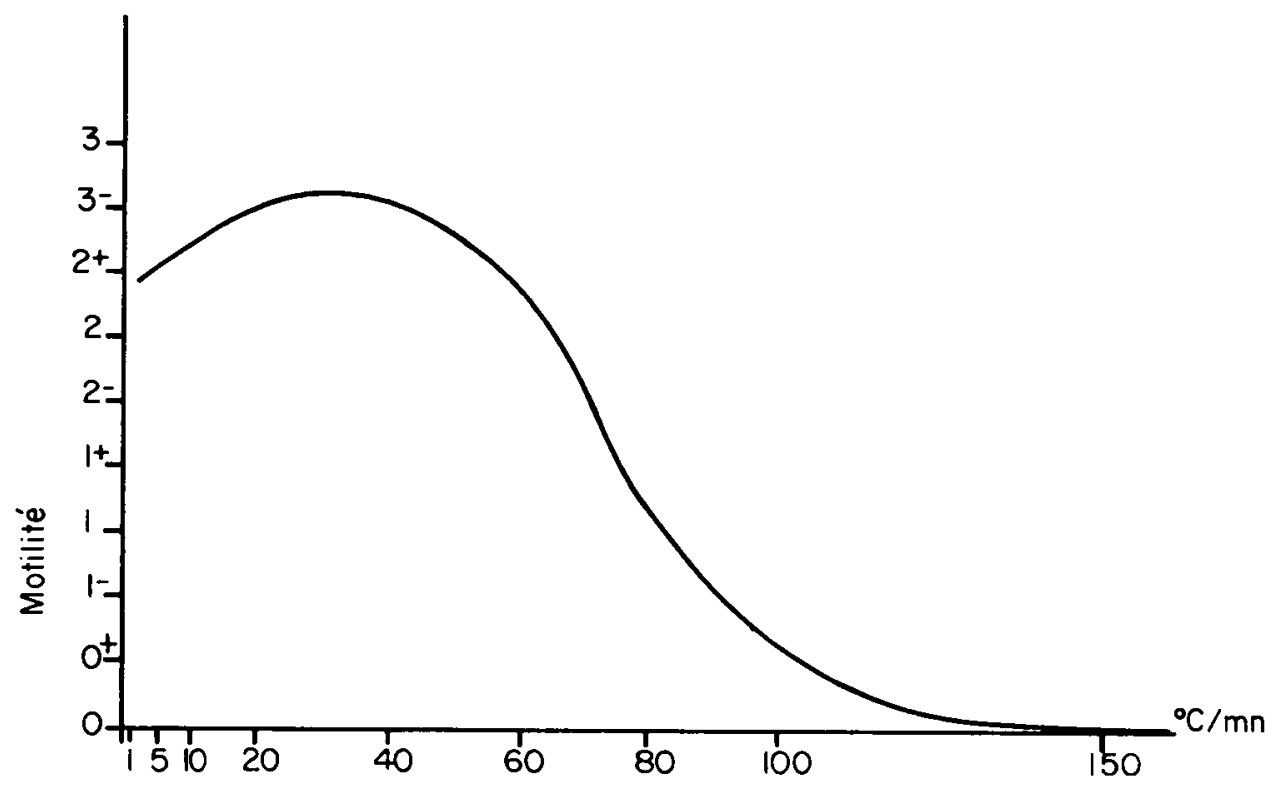

Figure 5: Influence de la vitesse de congélation sur la motilité des spermatozoides après décongélation.

La congélation est réalisée en paillettes dans les vapeurs d'azote liquide ; la motilité du sperme frais est de 3 .

La figure 6 montre que le pouvoir fécondant du sperme a une évolution identique en fonction de l'accroissement de la temperature de dégel pour les deux dilueurs utilisés. et que le passage des pellets dans l'azote liquide n'affecte pas les résultats obtenus

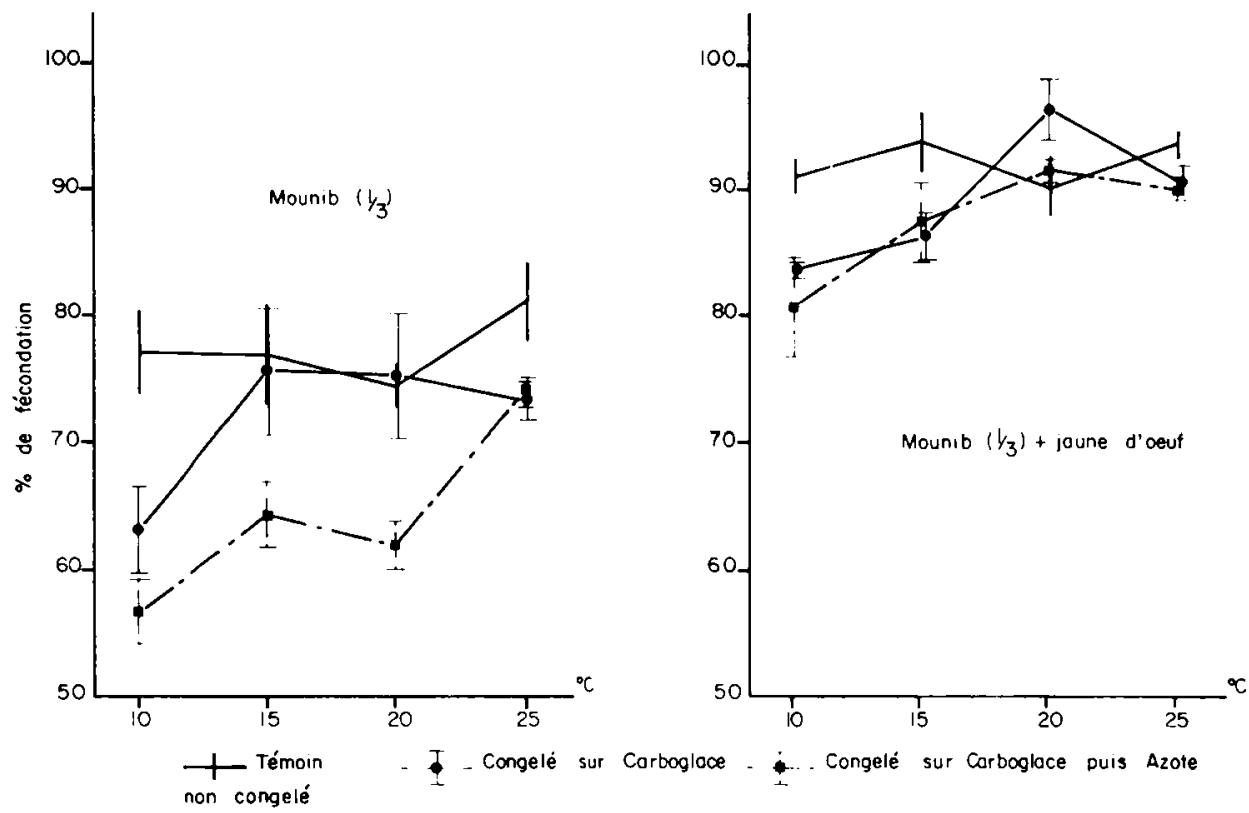

Figure 6 : Influence de la température de décongélation des pellets sur le pouvotr fécondant. 
La difference observée entre congelé et témoin pour la temperature de dégel de $10^{\circ} \mathrm{C}$ est très significative $(P<0,01)$ lorsque le sperme est dilué dans le dilueur $M$, mais est moins importante $(P<0,05)$ lorsque $M W$ est utilisé, ce qui accrédite encore l'effet favorable du jaune d'œuf. On constate d'autre part que. lorsque la température du DIA augmente, le pouvoir fécondant du sperme congelé s'améliore et rejoint le niveau des témoins qui reste stable.

Tableau 7 : Influence de la congélation et de la température de décongélation des pellets sur le pourcentage d'éclosions.

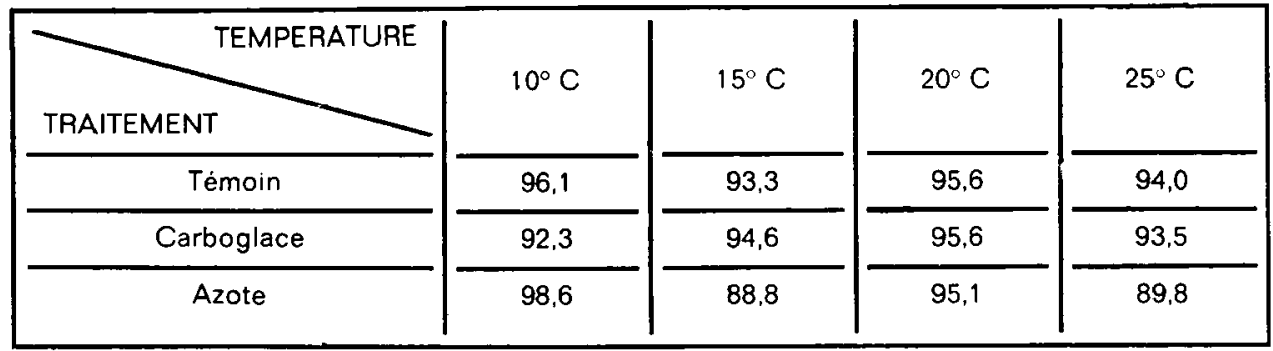

Tableau 8 : Mortalité pendant la résorption vitelline d'alevins issus d'ovules fécondés par du sperme trais et congelé.

\begin{tabular}{|c|c|c|c|c|}
\hline \multirow[b]{3}{*}{ Nombre d'alevins au départ } & \multicolumn{2}{|c|}{ SPERME $N^{\circ} 1$} & \multicolumn{2}{|c|}{ SPERME $N^{\circ} 2$ * } \\
\hline & Témoin & Congelé & Témoin & Congelè \\
\hline & 879 & 820 & 713 & 847 \\
\hline Nombre de morts & 60 & 52 & 32 & 38 \\
\hline Mortalité en pourcentage & 6,8 & 6,3 & 4,4 & 4,4 \\
\hline
\end{tabular}

* Les deux spermes sont testés sur un même pool d’ovules.

5) Influence de la congélation sur la mortalité embryonnaire et pendant la résorption vitelline

Le tableau 7 montre que ni la temperature finale de stockage des pellets (79 ou $196^{\circ} \mathrm{C}$ ), ni la temperature observee pour la mise en présence des gamètes, n'influencent le pourcentage d'éclosion. II apparait donc que la congélation n'augmente pas la pro. portion des avortements tardifs pendant la période embryonnaire ou lors de l'éclosicn Le tableau 8 montre que la mortalité durant la periode de résorption vitelline siest avéréc faible et peu variable, que les alevins soient issus de sperme frais ou congelé. Aucun pic de mortalité et aucune malformation particulière n'ont èté observés.

6) Variation intersperme dans l'aptitude à la congélation et la conservation à l'ètat congelé

Dans cette expérience réalisée en fin de période de spormiation (mi-février), les spermes de 9 mâles et un pool constitué par mélange de ces 9 spermes (avec participation 
égale de chaque sperme), ont èté utilisès. Le pouvoir fècondant a èté testé avant congélation, avec ou sans dilution dans le dilueur de congélation. Après congélation, quatre séries de pellets ont èté stockées dans les conditions suivantes :

- série 1 : stockage de quelques heures sur carboglace;

- séries 2, 3 et 4 : stockage de quelques heures, une semaine et six mois (respectivement) dans l'azote liquide.

Un même pool d'ovules a été utilisé pour l'insémination avec les séries 1 et 2 e: le sperme non congelé. Pour la série 3, la qualité du pool d'ovules utilisé a été évaluée avec un nouveau pool de sperme frais. Pour la série 4 , les ovules ont été obtenus (en août) à partir de femelles placées en photoperiode decroissante $(16 L \rightarrow 8 L)$ depuis 4 mois et un témoin a également été réalisé avec le sperme frais d'un mâle placè dans les mêmes conditions de photopériode.

Les résultats obtenus ont révélé que les différences individuelles observèes entre les 9 mâles sont faibles $(P<0,1)$ quels que soient le type et la durée de stockage utilisés. Par contre, bien que le pouvoir fécondant du pool de sperme (fig. 7) soit équivalent à

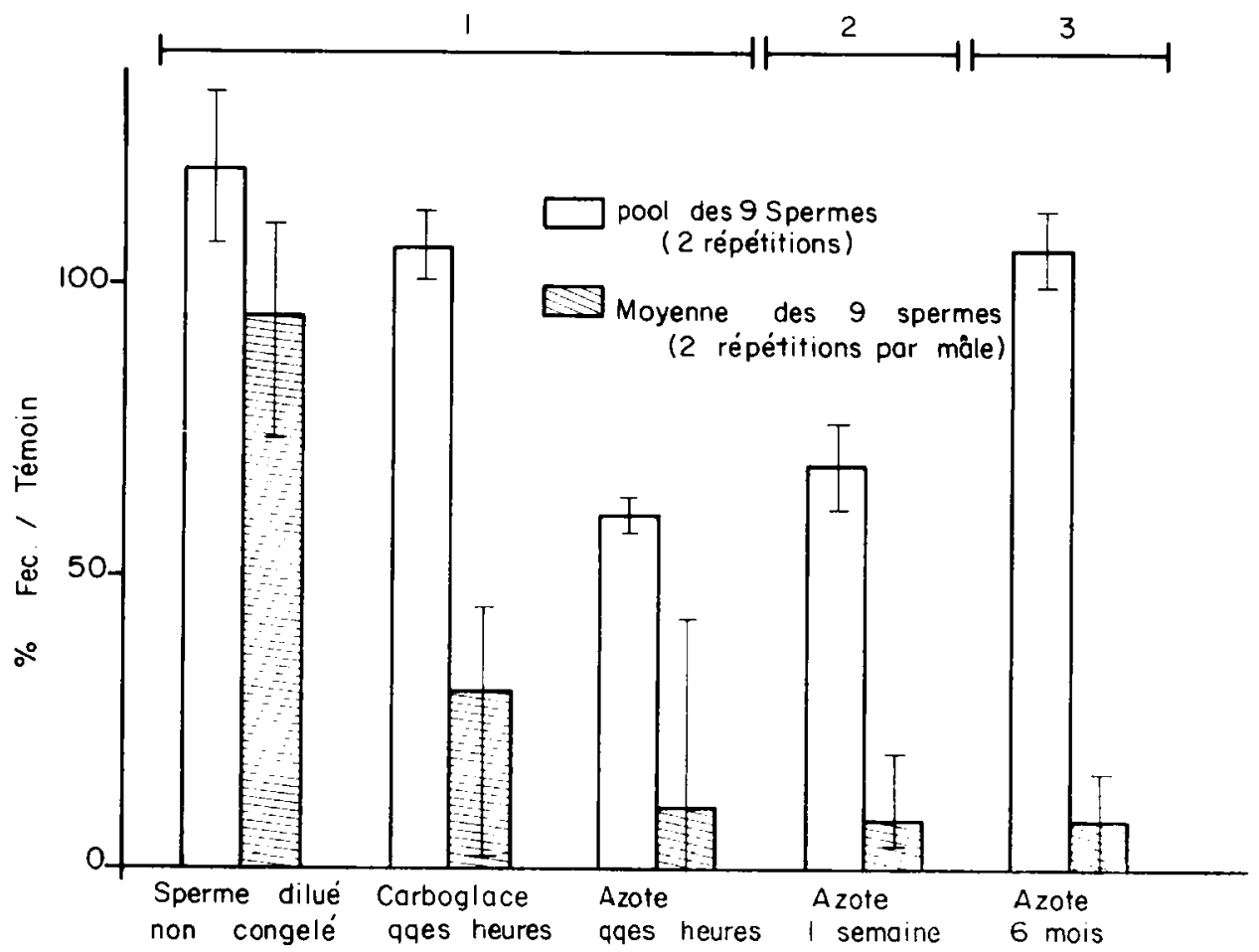

Figure 7 : Aptitude à la congélation et à la conservation à l'état congelé du sperme de 9 mâles et du pool de ces spermes en fin de période de spermiation.

Les écarts représentés correspondent aux limites inférieures et supérieures observées ;

Les témoins de référence (sperme non dilué, non congelé), sont les suivants :

en 1 : pour le pool : 40,7\% (LI $=38,5$, LS $=42,9 \%$ )

pour la moyenne des mâles : $49,6 \%(L I=43,5$, LS $=54,8 \%$ )

en $2: 88,7 \%(L I=86,8$, LS $=90,6 \%)$

en $3: 9,1 \%(L I=8,3$, LS $=10 \%)$. 
celui des différents mâles avant congélation. son pouvoir fécondant savère supérieur à celui du meilleur mâle pour les séries 1,3 et 4 de congelation (respectivement : $P<0.05$. $P<0,001 . P<0,05)$; pour la série $A$, il est équivalent au meilleur des mâles, mais reste supérieur à chacun des autres mâles $(P<0,01)$.

Il apparait d'autre part que les pourcentages de fécondation obtenus après simple dilution des spermes (sans congélation) ne sont pas différents de ceux obtenus avec le sperme pur. II se confirme donc que le dilueur MW. (1/3) est sans effet sur le pouvoir fécondant du sperme non congelé. La figure 5 montre également que la congélation et le stockage quelques heures sur carboglace diminuent le pouvoir fécondant de manière significative $(P<0,001)$ pour l'ensemble des 9 mâles, le pool restant néanmoins au niveau de son témoin. Le passage des pellets dans l'azote liquide provoque une nouvelle baisse du pouvoir fécondant. Cependant, cette dernière observation qui apparait en contradiction avec les résultats précédents, doit être considèree comme un artefact consécutif à uno congélation tardive (après prélèvement du sperme) des pellets de la serie 2. La figure 7 montre d'autre part que le pouvoir fécondant ne diminue pas après une durée de stockage de 6 mois, aussi bien pour le pool que pour l'ensemble des 9 mâles.

\section{7) Influence de la concentration du sperme en spermatozoïdes}

La concentration en spermatozoides a été déterminée sur les spermes de 10 mâles Leur pouvoir fécondant a èté testé après congélation et stockage quelques heures sur carboglace.

La figure 8 montre que, pour des concentrations en spermatozoides voisines, le pouvoir fécondant du sperme accuse après congelation de très importantes variations. Malgre le nombre restreint d'observations, il apparait donc que la concentration en spermatozoides ne peut être considèee comme un paramètre d'évaluation a priori du pouvoir fécondant du sperme congelé.

\section{8) Relation entre motilité et pouvoir fécondant du sperme au dégel}

La motilité des spermatozoides lors de la décongélation a été systématiquement évaluée au cours de tous les tests de fécondation. La figure 9 rassemble les résultats do ces évaluations et des tests de fécondation. II apparait que le pourcentage de fécondation croit avec la motilité, cet accroissement ètant particulièrement marqué dans la zone de motilité " 1 " ( $P<0,05)$. Ces résultats montrent en outre que des taux de fécondation relativement élevés sont obtenus avec des spermatozoìdes dont l'intensité de motilité est faible.
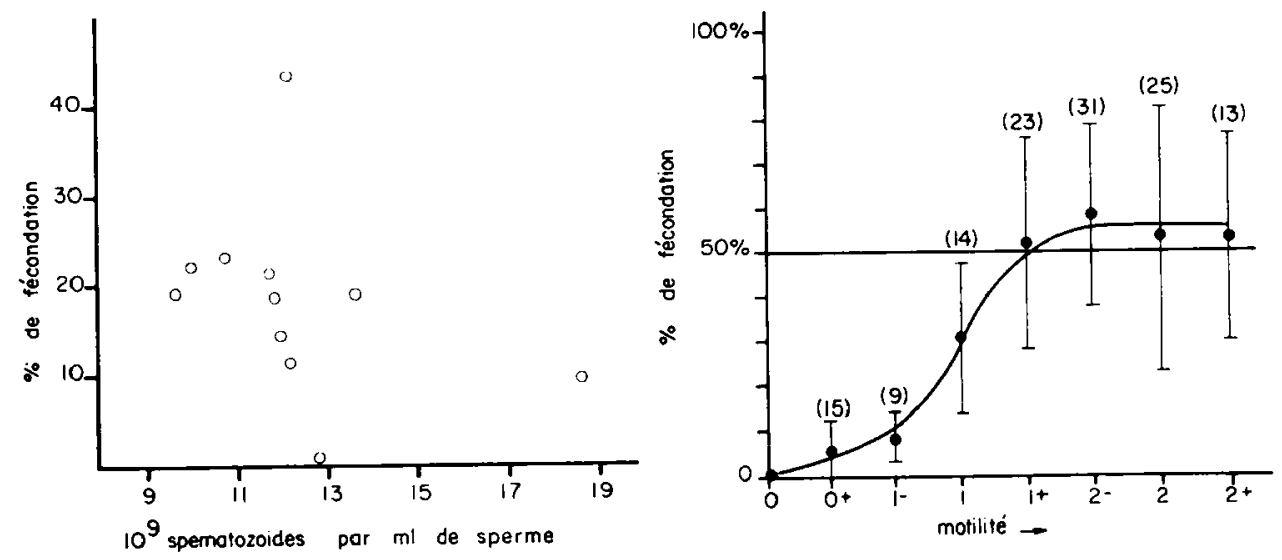

Figure 8 : Relation entre la concentration en spermatozoides du sperme congelé et son pouvoir fécondant.

Figure 9 : Relation entre motilité et pouvoir fécondant des spermatozoides après décongélation. 


\section{DISCUSSION}

Les résultats obtenus montrent que la cryoconservation du sperme de Truite arc-en-ciel est possible, au moins à moyen terme (quelques mois); plusieurs dilueurs ont donné des résultats satisfaisants et une technique de congélation-décongélation-insémination a pu être établie.

La recherche s'est limitée à comparer et à améliorer deux dilueurs antérieurement utilisés avec des succès partiels : les dilueurs de Mounib (MOUNIB, 1978) et MENEZO B.: (BILLARD, 1979). Le dilueur de Mounib, caractérisé par la présence de bicarbonate de potassium et de sucrose, se révèle incontestablement supérieur au milieu Menezo, et l'addition de jaune d'œuf en améliore les performances. Le milieu Mounib, additionné de $10 \%$ de jaune d'œuf et de $10 \%$ de DMSO, a donc été retenu et les conditions d'utilisation sont les suivantes:

- dilution du sperme $1 / 3$, vitesse de congélation en paillettes comprise dans une gamme de 10 à $40^{\circ} \mathrm{C} / \mathrm{mn}$ (ou même 1 à $60^{\circ} \mathrm{C} / \mathrm{mn}$ ), décongélation rapide en une dizaine de secondes (dans le dilueur d'insémination et directement en présence des ovules lorsque le sperme est congelé sous forme de pellets).

Les spermatozoides subissent incontestablement des altérations et le nombre de spermatozoïdes cryopréservés à mettre en œuvre lors de l'insémination artificielle doit être augmenté (facteur 10) pour égaler les pourcentages de fécondation obtenus avec le sperme frais. Les spermatozoïdes fécondants conduisent néanmoins à un développement embryonnaire et post-embryonnaire normal. L'aptitude du sperme a être congelé varie légèrement d'un mâle à l'autre et la mise en pool des spermes de plusieurs mâles conduit à un meilleur taux de fécondation que l'ensemble des valeurs individuelles en fin de période de spermiation.

\section{Un certain nombre de ces points appellent discussion}

\section{- La mise au point d'un dilueur de congélation :}

L'addition de jaune d'œuf et à un moindre degré de BSA au milieu de Mounib améliore ses performances, montrant que le bicarbonate de potassium et le sucrose ne garantissent que partiellement une bonne survie des spermatozoïdes. L'action favorable de composés organiques comme le jaune d'œuf pourrait être liée à un effet protecteur sur les membranes des spermatozoìdes au niveau desquelles il se fixerait de façon réversible (WATSON, 1975).

Les performances moins bonnes du milieu Menezo. bien que beaucoup plus complet semblent devoir être attribuées, pour une part au moins, à un taux de potassium insuffisant, ce qui entraine une motilité des spermatozoïdes conduisant à un épuisement prématuré. Comme le chlorure de potassium (KCI) (SCHLENK et KAHMANN, 1937: BILLARD 1975), le bicarbonate de potassium $\left(\mathrm{K}_{2} \mathrm{CO}_{2}\right)$ a un effet inhibiteur de la motilité (STOSS et al., 1977) et rend compte de l'immobilité des spermatozoïdes dans le dilueur Mounib Bien que STOSS et al. (1977) observent des modifications morphologiques des spermatozoides en présence de carbonates, il ne semble pas que le dilueur lui-même ait un effnt toxique. TRUSCOTT et al. (1958) signalent d'autre part la nature toxioue du DMSO sur to sperme pur, mais de même que ERDAHL et al. (1978). nous n'avons pas retrouvé cottn toxicité. de sorte que la baisse de fécondance du sperme cryopréservé est bien due à la congélation elle-même et ne s'additionne pas d'un effet délétère initial du dilueur Cette baisse de fécondance peut être compensée, au moins partiellement par une rédiction du taux de dilution du sperme à l'insémination $\left(10^{-2}\right.$ au lieu de $\left.10^{-3}\right)$, le taux limite de dilution avec du sperme frais étant généralement de $10^{-3}$ et quelquafois de $10^{-4}$ avec des spermes de qualité exceptionnelle. L'association milieu Mounib-iaune d'œuf-DMSO nf conserve donc pas intéaralement les performances du sperme frais et reste derfectib'e. Dans ce sens. on a pu remarquer que l'effet favorable du iaune d'œuf s'atténue lorsaur sa concentration et celle du DMSO augmentent; cependant. dans notre étude. la concentration de ces composants et la difution du soerme avant conaélation variant simul- 
tanément, l'influence de ces paramètres ne peut être dissociée. ll pourrait donc être benefique de rechercher le rapport optimum en jaune d'œuf et en DMSO pour la clilution 1/u qui s'avère la plus favorable.

\section{- Définition des vitesses de congélation et de décongélation :}

La méthode de congélation en pellets, au sein desquels la vitesse de congélation n'est pas uniforme (LIGTHFOOT et al., 1969) ne se prête pas à l'étude de ce raramètre. Son influence a donc été évaluée avec la méthode de congélation en pallettes dont le faible diametre ne permet pas l'etablissement d'un gradient de temperature. Dans ce dernier cas, le sperme au dégel présente une imporiante motilité pour des vitesses de congélation comprises entre 1 et $60^{\circ} \mathrm{C} / \mathrm{mn}$; par contre, des vitesses de congélation plus élevées sont défavorables: ERDAHL et GRAHAM (1978) indiquent cependant de bons résultats pour une vitesse de $80^{\circ} \mathrm{C} / \mathrm{mn}$. Cette observation basée seulement sur la motilité demande à être confirmée en se référant au pouvoir fécondant.

Nous avons pu montrer de façon plus sensible l'importance de la vitesse de décongélation sur la survie des spermatozoides. L'accroissement de la température de décongélation a en effet permis d'améliorer le pouvoir fécondant du sperme congelé et d'atteindre celui du contrôle. La stabilité du pouvoir fécondant du témoin (quelle que soit la température du DIA) montre d'une part que l'amélioration du pouvoir fécondant du sperme congelé est bien due à un accroissement de la vitesse de décongélation et, d'autre part, que l'utilisation de DIA à température élevée en début d'insémination n'affecte ni les spermatozoides, ni les ovules. Ce dernier point s'explique par le fait que la température ambiante, les ovules et la boite d'insémination artificielle étant à $10^{\circ} \mathrm{C}$, la tempé. rature du DIA ne se maintient pas à son niveau initial et chute rapidement. BILLARD et GILLET (1975) n'observent en effet une influence défavorable sur les pourcentages de fécondations que lorsque les gamètes sont maintenus plusieurs minutes à des températures élevées. L'influence favorable d'un dégel rapide est un phénomène déjà décrit en cryo. biologie; il permet en effet de limiter les remaniements cristallins qui peuvent endommager gravement les cellules lorsque la vitesse de décongélation est faible (MAZUR, 1977). ainsi que le temps d'action des solutions hypertoniques qui apparaissent vers $-30^{\circ} \mathrm{C}$ (BILLARD et DUPONT, 1975).

\section{- Le problème de la durée de stockage du sperme congelé :}

Le sperme congelé supporte sans dommage le passage de $-79^{\circ} \mathrm{C}$ à $-196^{\circ} \mathrm{C}$ et les pellets ont donc été stockés dans l'azote liquide. Dans la plupart des expériences, la durée de stockage n'a pas excédé une semaine et, lors de l'insémination réalisée après 6 mois, la médiocre qualité des ovules limite la portée des conclusions quant à la possibilité de conserver le sperme sur une periode prolongée; cependant, MOUNIB (1978) et STOSS (1978) font état de conservation de plusieurs mois et même d'une année.

\section{- Variation de l'aptitude du sperme à la congélation :}

Si l'aptitude du sperme à la congélation varie peu au sein d'un même groupe de mâles, elle évolue cependant au cours de la période de spermiation. En effet, en début de spermiation (décembre) les taux de fécondation enregistrés avec du sperme congelé (individuellement) étaient de l'ordre de 50 à $60 \%$, alors qu'à la mi-février le maximum observé était de $28 \%$.

Des diminutions de la motilité et de l'aptitude à la congélation ont déjá été rapportées chez la Truite (BILLARD et BRETON, 1976) et le Bar (BILLARD et al. 1977), et ont été reliées à des phénomènes de vieillissement du sperme. En fin de période de spermiation, CHEMAYEL (1975) observe un appauvrissement du spectre enzymatique chez la Truite. Ces phénomènes de vieillissement pourraient expliquer l'effet favorable du mélange des spermes, si l'on admet que la faible aptitude à la congélation du sperme de chacun des mâles résulte de modifications diffétentes. Les spermatozoïdes et les liquides séminaux pourraient avoir "vieillis " de façon hétérogène, de telle sorte que certains liquides séminaux auraient conservé un pouvoir protecteur dont viendraient 
bénéficier les spermatozoídes moins altérés d'autres spermes, dotés d'un environnement mineral ou organique moins favorable pour assurer leur résistance à la congélation. Une telle hypothèse ne doit pas totalement surprendre si l'on sait qu'un effet favorable du mélange des spermes de taureaux de souches génétiques différentes a dejà été observé après congélation (CORTEEL, communication personnelle). Le problème de la qualité du sperme se trouve ainsi posé, de même que celui de critères d'appréciation de l'aptitude à la congélation. Nous avons vu que la concentration en spermatozoides du sperme ne peut pas constituer un critère solide. Par contre, la motilité après décongélation (fig. 9) donne une idée grossière du succès escompte en pouvoir fécondant, ce qui rejoint les observations de TRUSCOTT et al. (1968) qui constataient que les spermes les plus motiles étaient invariablement les plus fertiles. Pour disposer d'un critère plus précis, il semble, d'après les données précedentes, que la recherche doive siorienter vers l'analyse des constituants ioniques ou organiques du liquide séminal, tels que les protéines ou l'équipement enzymatique.

\section{- Généralisation de la technique de congélation à d'autres espèces :}

Des essais d'application de la technique de congélation au sperme de Carpe, de Brochet et d'une espèce marine, le Marbre, ( $L$. Mormyrus), ont donne des résultats encourageants (LEGENDRE, non publié). II apparait cependant que, si des analogies existent entre les réactions présentées par chaque type de sperme en fonction de la nature du Jilueur, des différences sont aussi observees. On constate en effet que le sucrose seul, ou en association avec d'autres composants, permet toujours une bonne survie des spermatozoides pour les quatre espèces abordèes et que le dilueur Mounib peut être utilisé avec succès chez la Truite, la Carpe et le Brochet. Pourtant il semble que le sucrose n'agisse pas toujours de manière identique, puisque avant congélation il immobilise les spermatozoides chez les espèces d'eau douce, alors que, chez le Marbré, une solution de sucrose induit la motilite au même titre que l'eau de mer. Chez la Carpe, son utilisation conduit parfois à une agglutination des spermatozoìdes après dégel. D'autre part, le $\mathrm{DCSB}_{4}$, efficace pour le sperme de Bar (DUPONT, 1976). n'autorise pas une protection satisfaisante chez le Marbré.

II s'avère donc qu'une ètude spécifique des composants minéraux et organiques nécessaires pour préserver les spermatozoiles durant la congélation doit être menée pour chaque espèce étudiée.

\section{REMERCIEMENTS}

Ce travail a été pris en charge par le Conseil Supérieur de la Pêche. Nous remercions Aline SOLARI et Bernard CHEVASSUS pour leur aide dans l'interpretation statistique des résultats. Nous devons à Messieurs CORTEEL, MENEZO et PAQUIGNON de fructueuses discussions sur les problemes de cryopréservation des gamètes et les commentaires critiques du $\mathrm{Pr}$. THIBAULT ont été particulièrement appréciés.

\section{RESUME}

Une sèrie d'expériences a été conduite pour la mise au point d'une technique de cryoconservation du sperme chez la truite arc-en-ciel.

Le dilueur de congélation de Mounib (1978), additionné de $10 \%$ de jaune d'œuf et de $10 \%$ de DMSO, a èté retenu et les conditions d'utilisation qui autorisent la meilleure conservation du pouvoir fécondant sont les suivantes : congélation en pellets de $100 \mu$ ou en paillettes de $250 \mu l$ pour un abaissement de tempèrature de 10 à $40^{\circ} \mathrm{C} /$ minute, décongélation rapide en une dizaine de secondes. Cependant les spermatozoides subissent incontestablement des dommages durant le processus de congélation et leur nombre lors de l'insémination doit être augmenté pour égaler les pourcentages de fécondation obtenus avec le sperme frais; néanmoins, les spermatozoides fécondants conduisent à un développement embryonnaire et post-embryonnaire normal. 
Une baisse de l'aptitude à la congélation a été constatée en fin de période de spermiation; celle-ci a été reliée à des phénomènes de vieillissement du sperme et peut être compensée par la mise en pool des spermes de plusieurs mâles. Nous avons constate d'autre part qu'après décongélation les spermes les plus motiles sont les plus fécondants. condants.

\section{SUMMARY}

This paper reports a series of experiments conducted to improve a procedure of sperm cryopreservation in rainbow trout.

The Mounib's medium (1978), to which was added $10 \%$ egg yolk and $10 \%$ DMSO. was chosen and the best preservation of the fertilizing ability was obtained under the following conditions : dilution ratio $1 / 3$, freezing in pellets $(100 \mu l)$ or in straws $(250 \mu l)$ with a freezing rate of 10 to $40^{\circ} \mathrm{C} / \mathrm{min}$, quick thawing (in $10 \mathrm{~s}$ ). However, the spermatozoa were undoubtly damaged during the freezing procedure and their number at the moment of insemination had to be raised to approximate the same fertilization rate as that of the non frozen sperm; nevertheless, the fertilizing spermatozoa lead to a normal embryonic and post-embroyonic development

A decrease in the freezing ability was observed at the end of the period of spermiation; this may be put in relation with sperm ageing and can be compensated for by pooling the semen of several males. It was also observed that after thawing the most motile sperm exhibited the highest fertilization rate.

\section{BIBLIOGRAPHIE}

BILLARD R., JALABERT B., 1974. L'insémination artificielle de la truite (Salmo gairdneri Richardson). II - Comparaison des effets de différents dilueurs sur la conservation de la fertilité des gamètes avant et après insémination. Ann. Biol. anim. Bioch. Biophys., 14, 601-610.

BILLARD R., GILLET C., 1975. Effets de la température sur la fécondation et la survie des gamètes chez la truite arc-en-ciel (Salmo gairdneri). Bull. Fr. Pisc., 259, 53-65.

BILLARD R., 1975. L'insémination artificielle de la truite (Salmo gairdneri Richardson) IV - Effets des ions $\mathrm{K}^{+}$et $\mathrm{Na}^{+}$sur la conservation du pouvoir fécondant des gamètes. Bull. Fr. Pisc., 256, 88-100.

BILLARD R., DUPONT J., 1975. Etudes sur la congélation du sperme de poissons marins (Bar, Daurade, Turbot) CR. d'activité CNEXO, $15 \mathrm{pp}$

BILLARD R., BRETON B., 1976. Sur quelques problèmes de physiologie du sperme chez les poissons téléostéens. Rev. Trav. Inst. Pêches Marit., 40, 501-503.

BILLARD R., 1977. Utilisation d'un système Tris-glycocolle pour tamponner le dilueur d'insemination pour truite. Bull. Fr. Pisc., 264, 102-112.

BILLARD R., DUPONT J., BARNABE G., 1977. Diminution de la motilité et de la duree de conservation du sperme de Dicentrarchus labrax L. (poisson téléostéen) pendant la période de spermiation. Aquaculture, 11, 363-367.

BILLARD R., 1979. Some data on gametes preservation and artificial insemination in teleost fish. Actes de colloque CNEXO, 8, 59-73.

CARPENTIER P., 1977. Essais de conservation, de transport des gamètes et des œufs fécondés et études des conditions optimales de résorption vésiculaire chez les Salmonidés. DEA Physio. Reprod., Université Paris VI

CHEMAYEL M. 1975. Etude de la variabilité du pouvoir fécondant du sperme en relation avec ses caractéristiques chez la truite arc-en-ciel (Salmo gairdneri Richardson) Thèse Doctorat $3^{\circ}$ Cycle, Université Paris VI. 
DUPONT J., 1976́. Etude sur la congélation du sperme de poissons marins (Bar, Daurade). C.R. activité CNEXO, $10 \mathrm{pp}$.

ERDAHL D.A., GRAHAM E.F., 1978. Cryopreservation of salmonid spermatozoa. Cryobiol., $15,362-364$.

GRAYBILL J.R., HORTON H.F., 1969. Limited fertilization of steelhead trout eggs with cryopreserved sperm. J. Fish. Res. Bd. Can., 26, 1400-1404.

HOYLE R.J., IDLER D.R., 1958. Preliminary results in the fertilization of eggs with frozen sperm of Atlantic salmon (Salmo salar). J. Fish. Res. Bd. Can., 25, 1295-1297.

LEGENDRE M. BILLARD R., 1980. Cryopreservation of rainbow trout sperm by deep freezing. Reprod. Nutr. Develop., 20, (6) sous presse.

LIGHTFOOT R.J., SALAMON S., 1969. Freezing ram spermatozoa by the pellet method. Aust. J. biol. Sci., 22, 1547-1560.

MAZUR P., 1977. The role of intracellular freezing in the death of cells cooled at supraoptimal rate. Cryobiol. 14, 251-272.

MENEZO Y., 1976. Milieu synthétique pour la survie et la maturation des gamètes et pour la culture de l'œuf fécondé. C.R. Acad Sci. Paris, série D, 282, 1967-1970.

MERYMAN H.T., 1971. Cryoprotective agents. Cryobiol., 8, 173-183.

MOCZARSKI M., 1977. Deep freezing of carp (Cyprinus carpio L.) sperm. Bull. Acad. Pol. Sci., Ser. Sci Biol. 25, 187-189.

DE MONTALEMBERT G., BRY C., BILLARD R., 1978. Control of reproduction in Northern Pike. Am. Fish. Soc., Spec. Publi., 11, 217-225.

MOUNIB M.S., EISAN J.S., 1968. Carbon dioxide fixation by spermatozoa of cod. Comp. Biochem. Physiol., 25, 703-709.

MOUNIB M.S., 1974. NAD and NADP malic enzymes in spermatozoa of mammals and fish. FEBS Letters, 48, 79-84.

MOUNIB MS., 1978. Cryogenic preservation of fish and mammalian spermatozoa. J. Reprod Fert., 53, 13-18.

NAGASE H., 1964. Deep freezing bull semen in concentrated pellet form. I - Factors affecting survival of spermatozoa. Proc. Int. Congr. Reprod. anim. Insem. Artif., Trento, 4. 410-415.

OTT A.G., HORTON H.F., 1971 a. Fertilization of chinook and coho salmon eggs with cryopreserved sperm. J. Fish. Res. Bd. Can., 28, 745-748.

OTT A.G. HORTON H.F., 1971 b. Fertilization of steelhead trout (Salmo gairdneri) eggs with cryopreserved sperm. J. Fish. Res. Bd. Can. 28, 1915-1918.

PETIT J., JALABERT B. CHEVASSUS B., BILLARD R., 1973. L'insémination artificielle de la truite (Salmo gairdneri Richardson). I - Effet du taux de dilution, du $\mathrm{pH}$ et de la pression osmotique du dilueur sur la fécondation. Ann. Hydrobiol., 4, 201-210.

SANCHEZ-RODRIGUEZ M., 1975. Contribution à l'étude de l'insémination artificielle de la truite (Salmo gairdneri); les possibilités de manipulation des gamètes et de conservation du sperme. DEA Physiol. Reprod., Univ. Paris VI.

SCHLENK W. KAHMANN H., 1937. Die chemische zusammensetzung des spermaliquors und ihre physiologische bedeutung. Untersuchung am Forellensperma. Biochem. Z., 295, 283-301.

STEIN H., BAYRLE H., 1978. Cryopreservation of the sperm of some freshwater teleosts. Ann. Biol. anim. Bioch. Biophys., 18, 1073-1076. 
STOSS נ., BUYÜKHATIPOGLU S., HOLTZ W., 1977. Ber einflub bestimmter elektrolyte auf die Bewegungsanslösung bei spermatozoen der Regenbogenforelle (Salmo gairdneri. Zuchthyg., 12, 178-184.

STOSS J., BUYUEKHATIPOGLU S., HOLTZ W., 1978. Short-term and cryopreservation of rainbow trout (Salmo gairdneri Richardson) sperm. Ann. Biol. anim. Bioch. Biophys.. 18. $1077-1082$.

TRUSCOTT B., IDLER D.R., HOYLE R.J., FREEMAN H.C., 1968. Sub zero preservation of atlantic salmon sperm. J. Fish. Res. Bd. Can., 25, 363-372.

TRUSCOTT B., IDLER D.R., 1969. An improved extender for freezing atlantic salmon spermatozoa. J. Fish. Res. Bd. Can., 26, 3254-3258.

WATSON P.F., 1975. The interaction of egg yolk and ram spermatozoa studied with a fluorescent probe. J. Reprod. Fert., 42, 105-111. 